\title{
Aorto-esophageal fistula: A rare fatal case of gastrointestinal hemorrhage caused by foreign body
}

\author{
Omar Toumi, Sadok Ben Jabra, Ammar Mahmoudi, Hanene Zenati, Mohamed Ben Khlifa, \\ Wassim Kallel, Khadija Zouari, Noomen Faouzi, Abdelaziz Hamdi \\ Department of Surgery, Fattouma Bourguiba Hospital, Monastir, Tunisia
}

\section{Email address}

toumiomar2010@yahoo.com (O. Toumi),sadok.b.j@live.fr(S. B. Jabra),mahmoudi_a1975@yahoo.fr(A. Mahmoudi), zenatihanen@yahoo.fr (H. Zenati),med_lemedecin@hotmail.fr (M. B. Khlifa),wassimmkallel@gmail.com (W. Kallel), khadija.zouari@rns.tn (K. Zouari), faouzinoomen@yahoo.fr (N. Faouzi), abdelaziz.hamdi@rns.tn (A. Hamdi)

\section{To cite this article:}

Omar Toumi, Sadok Ben Jabra, Ammar Mahmoudi, Hanene Zenati, Mohamed Ben Khlifa, Wassim Kallel, Khadija Zouari, Noomen Faouzi, Abdelaziz Hamdi. Aorto-Esophageal Fistula: A Rare Fatal Case of Gastrointestinal Hemorrhage Caused by Foreign Body. Journal of Surgery. Vol. 3, No. 1, 2015, pp. 1-3. doi: 10.11648/j.js.20150301.11

\begin{abstract}
Aorto-oesophageal fistula (AOF) is a rare cause of upper gastro-intestinal hemorrhage. A fistulous tract develops between the aorta and the esophagus most commonly in association with thoracic aortic aneurysms, foreign bodies, esophageal malignancy, and the presence of an aortic prosthetic graft or following trauma [1]. High mortality still accompanies the cases [2]. We report a case of AEF caused by a fish bone. Computed tomography demonstrated a fistula from the proximal descending thoracic aorta to the mid esophagus.This patient died when rupture into the esophageal lumen caused exsanguinating hemorrhage. Their clinical causes and treatment are reviewed and discussed below.
\end{abstract}

Keywords: Aortoesophageal Fistula, Foreign Body, Sengstaken-Blakemore Tube, Hematemesis

\section{Introduction}

An aortooesophageal fistula (AEF) is a fatal, and a rare cause of massive gastrointestinal bleeding. AEF has been related to aneurysm of the thoracic aorta, foreign bodies ingestion, oesophageal malignancy, the presence of an aortic prosthetic graft or following trauma [1].

Diagnostic and treatment protocols differ from those of other sources of gastrointestinal bleeding. As a result, emergency physicians should be aware of the presentation and management of patients with aorto-oesophageal fistula.

In this study, we report a case of a massive hemorrhage in the upper gastrointestinal tract resulting from an aortooesophageal fistula caused by a fish bone. We discuss methods to rapidely diagnose and treat patients in whom aorto-oesophageal fistula is suspected.

\section{Case Presentation}

A 76 year old women with no prior medical history, presented to the hospital emergency department with sharp pain retrosternally, franc haematemesis, some malaena after eating fish the previous day.

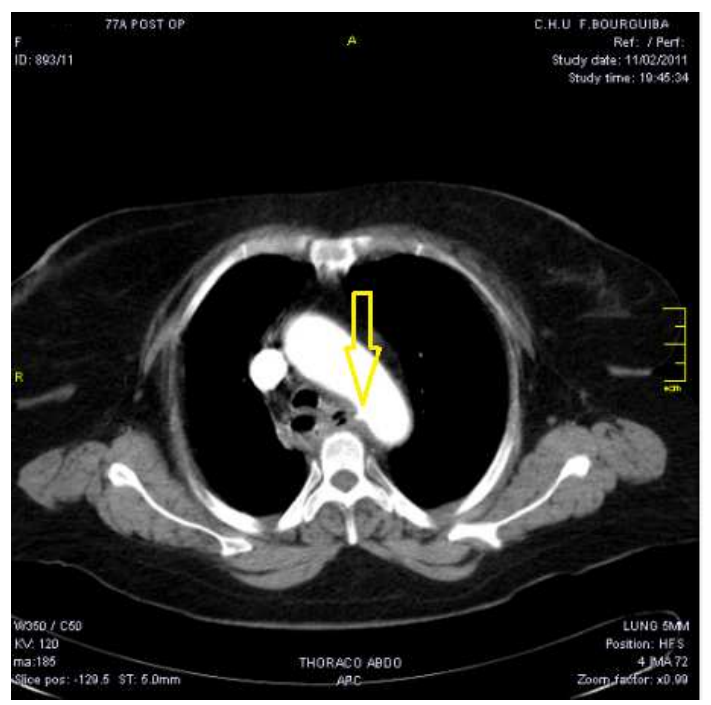

Figure 1. Chest CT showing a fistula between aortic cross and the lateral side of the esophagus

She was haemodynamically stable, the blood pressure was maintained around $140 / 80 \mathrm{mmHg}$, and the haemoglobin value remained steady at $12 \mathrm{~g} / \mathrm{L}$. The patient was admitted to 
the general surgical ward. An urgent upper gastrointestinal endoscopy was performed, where a fish bone was seen protruding from an ulcerated area in the oesophagus, $26 \mathrm{~cm}$ from the teeth, the fish bone was not touched and the oesophagoscope was carefully retired, a computed tomography (CT) angiogram was performed showing an oesophageal fistula between aortic cross and the lateral side of the esophagus (fig 1,2). One hour after the patient developed massive arteriel bleeding. The patient died on the operating table of an uncontrollable haemorrhage.

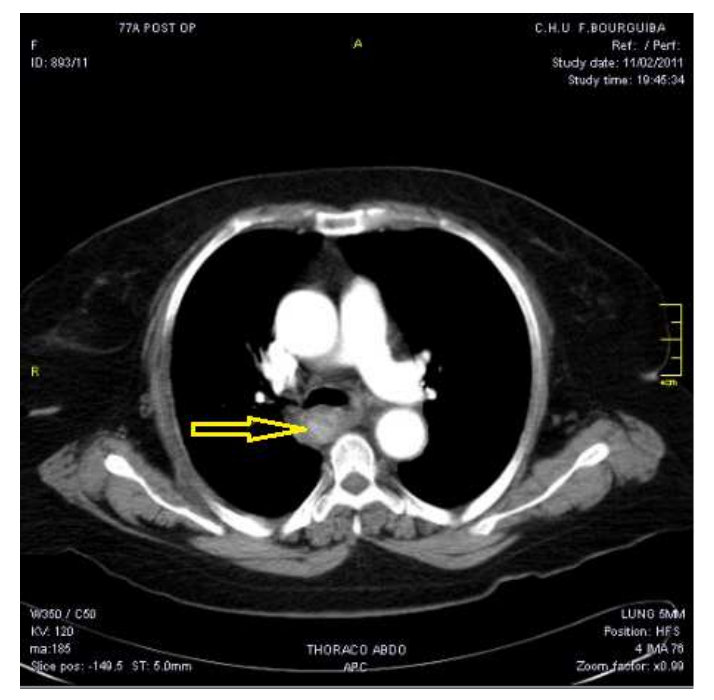

Figure 2. Chest CT showing a dilated and thickened side of the esophagus wall and intra-esophageal dense content related to fresh blood.

\section{Discussion}

The aortoesophageal fistula (AEF), is rare but life threatening complication of foreign body ingestion.

In addition to an FB retained in the esophagus predisposing causes of AEF include aneurysm of the thoracic aorta, thoracic malignancy, mediastinal infection, oesophagogastric reflu, and congenital thoracic aorta anomalies $[3,4,5,6]$ post-operative complications.

Approximately 500 cases of AOF have been reported in the litterature. Chiari $[7,6,8,9]$ first described the aortooesophageal syndrome in 1914, a painful esophageal injury followed by an asymptomatic interval until "signal hemorrhage" leads to exsanguinations hours to days later of .These symptoms are more specific in patient with AEF from FB that from over cause [10].

A review of all cases [11] aortooesophageal fistulas found that mid thoracic pain to present in $59 \%$ of cases, dysphagia in $45 \%$, and sentinal hemorrhage in $65 \%$.

Bleeding from aorto-oesophageal fistulas is characteristically distinguined from esophageal varices by his bright red aspect.

Other causes of upper gastrointestinal tract bleeding do not produce the volume of bleeding commonly seen with aortoesophaeal fistulas.

In the absence of clinical suspicion of AOF, non single examination reliably makes the diagnoses [1].
And majority of patients with AOF died without antemortem diagnosis once massive hemorrhagic occurs.

According to several autors [5], the most useful first investigation in patients with suspicion of AOF is upper gastrointestinal allowing to exclude the more causes of gastrointestinal hemorrhage. Classic endoscopic findings include direct visualization of pulsatile blood as was observed in our patient, or a pulsatile submucosal mass with adherent glot $[12,13]$. Osophageal mucosa may appear bluegray as a result of submucosal heamatoma[6].

There have been previous reports of value of contrast CT in AOF although demonstrations of true aorto-oesophageal communition are rare [14].

In this case, CT was demonstrated a communication between the oesophagus and aorta. In contrast, conventional barium studies do not have significant role in the diagnosis of $\mathrm{AOF}$, and has the major disadvantage that it will interfere with later angiography[5].

Operative repair of an aortoesophageal fistula is necessary as no survivors have been reported with non surgical management. Circulatory support with volume replacement and transfusion of blood products is essential in patients with active hemorrhage. Correction of coagulopathic and electrolyte abnormalities is indicated. Direct pressure on fistulas from Sengstaken-Blakemore tubes has provided temporary control of the exsanguinating hemorrhage.[15,16] Other measures such as radiographic embolization may be useful as a temporizing measure; however, delayed exsanguination after embolization can occur. [17] While awaiting operative intervention, broad-spectrum antibiotics should be administered as the esophageal flora may invade the mediastinum or the aorta [18]. With rapid diagnosis and surgical treatment, longterm survival is possible.[11,19,20,21,22]

\section{Conclusion}

Aortooesophageal fistulas secondary to foreign boy ingestion are rare. Their diagnosis is difficult. The ideal therapeutic is to forestall fatal rupture by prompt diagnosis and immediate surgery.

\section{References}

[1] Hollander JE, Quick G. Aortoesophageal fistula: a comprehensive review of the literature. Am J Med.1991; 91:279-87

[2] Ming-Ho Wu, Wu-Wei Lai . Aortoesophageal Fistula Induced by Foreign Bodies. Ann Thovac Surg 1992;54:155-6.

[3] Cheng LC ${ }^{1}$, Chiu CS. Foreign body-induced aortooesophageal fistula: a review of five cases and their management. Hong Kong Med J. 2006 Jun;12(3):219-21.

[4] Stephen L Kelly, Paul Peters, Murray J Ogg, Alan Li, Bernard M Smithers. Successful management of an aortoesophageal fistula caused by a fish bone - case report and review of literature J Cardiothorac Surg. 2009; 4: 21. 
[5] Maher MM, Murphy J, Dervan P, et al. Aorto-oesophageal fistula presenting as a submucosal oesophageal haematoma. Br J Radiol. 1998;71:972-974

[6] Heckstall, Robert L. et al. Aortoesophageal Fistula: Recognition and Diagnosis in the Emergency Department. Annals of Emergency Medicine , Volume 32, Issue 4, 502 505

[7] Chiari H. U“ ber Fremdko“ rperverletzung des Oesophagus mit Aorten perforation. Berlin Klin Wschr. 1914;51:7-9.

[8] Kieffer E, Chiche L, Gomes D. Aortoesophageal fistula: value of in situ aortic allograft replacement. Ann Surg. 2003 Aug;238(2):283-90.

[9] Sloop RD, Thompson JC: Aorto-esophageal fistula: Report of a case and review of the literature. Gastroenterology 1967;53:768-777.

[10] Hollander JE, Quick G: Aortoesophageal Fistula: A comprehensive review of the literature. Am J Med 1991, 91:279-287

[11] Hollander JE, Quick G: A comprehensive review of the literature. Am J Med 1991; 91:279-286.

[12] Han SY, Jander HP, Ho KJ: Aortoesophageal fistula. South Med J 1981; 74:1260-1262.

[13] Kirchgatterer A, Punzengruber C, et al: A rare case of gastrointestinal hemorrhage: Aortoesophageal fistula following repair of aortic dissection. Endoscopy 1997;29:137138 .
[14] Myers HS, Silber W. Oesophageal bleeding from aortoesophageal fistula due to aortic aneurysm. S Afr Med J. 1983 Jan 22;63(4):124-7.

[15] Magnussen I, Notander A, Rieger A, et al: Massive hematemesis due to an aortoesophageal fistula [case report]. Acta Chir Scand 1987;153:317-319.

[16] Yamada T, Sato H, Seki M, et al: Successful salvage of aortoesophageal fistula caused by a fish bone. Ann Thorac Surg 1996;61:1843-1845.

[17] Reedy FM: Embolization of aortoesophageal fistula: A new therapeutic approach [letter]. J Vasc Surg 1988;8:349-350.

[18] Sosnowik D, Greenberg R, Bank S, et al: Aortoesophageal fistula: Early and late endoscopic features. Am J Gastroenterol 1988;83:1401-1404.

[19] Kennedy FR, Cornwell ED, Camel J, et al: Aortoesophageal fistula due to gunshot wounds: Report of two cases with one survivor. J Trauma 1995;38:971-974.

[20] Pipinos II, Reddy DJ: Secondary aortoesophageal fistula. J Vasc Surg 1997;26:144-149.

[21] Wang N, Sparks SR, Bailey LL: Staged repair using omentum for posttraumatic aortoesophageal fistula. Ann Thorac Surg 1994;58:557-559.

[22] Luketich JD, Sommers KE, Griffith BP, et al: Successful management of secondary aortoesophageal fistula. Ann Thorac Surg 1996;62:1852-1854. 